\title{
CONTROLE DA MATURAÇÃo E CONSERVAÇÃo DA QUALIDADE PÓS-COLHEITA DE CAQUI 'FUYU' PELO MANEJO DO ETILENO'
}

\author{
JULIANA GOLIN KRAMMES², LUIZ CARLOS ARGENTA², MARCELO JOSÉ VIEIRA²
}

\begin{abstract}
RESUMO - O presente estudo avaliou o impacto do tratamento 1-MCP sobre a conservação da qualidade de caqui 'Fuyu', e como a exposição póscolheita ao etileno pode afetar a eficácia do 1-MCP. Os frutos foram colhidos em quatro diferentes estádios de maturação conforme indicado pelo índice de coloração da casca, após a maturação fisiológica. Frutos foram tratados com 0,1 e $1 \mu \mathrm{L} \cdot \mathrm{L}^{-1}$ de 1-MCP, um dia após a colheita, e mantidos a $23^{\circ} \mathrm{C}$ por até 45 dias, em ar ambiente contendo baixa $\left(\mathrm{d}^{\prime \prime} 0,1 \mu \mathrm{L} \cdot \mathrm{L}^{-1}\right)$ ou alta $\left(3 \pm 2 \mu \mathrm{L} \cdot \mathrm{L}^{-1}\right)$ concentração de etileno. $\mathrm{O}$ tratamento com 1 -MCP retardou o amolecimento da polpa, o desenvolvimento da coloração dos frutos e o aumento da produção de etileno, mas não alterou o teor de açúcares solúveis e a acidez titulável. A vida pós-colheita (período entre a colheita e o amolecimento da polpa) dos frutos foi aumentada por até 20 dias em relação aos frutos não-tratados. Frutos colhidos em estádio avançado de maturação apresentaram menor vida pós-colheita, independentemente do tratamento 1-MCP. O benefício do tratamento $1-\mathrm{MCP}$ foi maior para frutos colhidos precocemente e para frutos expostos a $3 \mu \mathrm{L} \cdot \mathrm{L}^{-1} \mathrm{de}$ etileno.
\end{abstract}

Termos para indexação: Diospyros kaki, firmeza da polpa, 1-MCP.

\section{POSTHARVEST CONTROL OF RIPENING AND QUALITY MAINTENANCE OF 'FUYU' PERSIMMON FRUIT BY ETHYLENE HANDLING}

\begin{abstract}
The present study determined the impact of 1-MCP treatment on the quality maintenance of 'Fuyu' persimmons, and how the postharvest exposure to ethylene could influence the 1-MCP effectiveness. The fruits were harvested at four different ripening stages according to skin color, after physiologic maturity. Fruits were treated with 0.1 and $1.0 \mu \mathrm{L} \cdot \mathrm{L}^{-1}$ of $1-\mathrm{MCP}$ one day after harvest, and then held at $23^{\circ} \mathrm{C}$ for up to 45 days in air with low $\left(\mathrm{d}^{\prime \prime} 0,1 \mu \mathrm{L} \cdot \mathrm{L}^{-1}\right)$ or high $\left(3 \pm 2 \mu \mathrm{L} \cdot \mathrm{L}^{-1}\right)$ ethylene $.1-\mathrm{MCP}$ treatment delayed fruit softening and changes of skin color and the increase in the ethylene production, whereas it had no effect on soluble solids content and on titratable acidity. The postharvest life (period between harvest and pulp softening) of fruits was increased for up to 20 days in comparison to control fruits. Persimmons harvested at advanced ripening stages had shorter postharvest life, regardless of 1-MCP treatment. The effectiveness of 1-MCP treatment was more pronounced in fruits harvested at early stages and for fruits exposed to $3 \mu \mathrm{L} \cdot \mathrm{L}^{-1}$ ethylene.
\end{abstract}

Index terms: Diospyros kaki, flesh firmness, 1-MCP.

\section{INTRODUÇÃo}

No Sul do Brasil, a colheita de caqui 'Fuyu' normalmente ocorre num curto período durante os meses de abril e maio. A adoção de técnicas para o aumento da conservação da qualidade dos frutos após a colheita é uma estratégia essencial para a expansão do período de oferta e redução da sazonalidade dos preços de caqui. A armazenagem refrigerada é a principal tecnologia para o controle da maturação e deterioração de frutos perecíveis, incluindo o caqui (MacRae, 1987). No entanto, assim como a maioria dos frutos tropicais e subtropicais, o caqui é sensível ao frio, podendo desenvolver desordens fisiológicas, dependendo da temperatura e do período de armazenagem (MacRae, 1987; Sargent et al., 1993).

A associação entre a síntese de etileno e a maturação póscolheita é demonstrada para caqui adstringente (Itamura et al., 1991; Nakano et al., 2003) e não-adstringente (Takata, 1982). Normalmente, o caqui apresenta baixa taxa de produção de etileno no ponto de colheita comercial (Takata, 1983; Itamura et al., 1997; Krammes, 2004), embora seja altamente sensível à ação de etileno (Takata, 1982; Crisosto et al., 1999). Considerando os efeitos do etileno sobre a maturação de caqui, não é raro que ocorra rápida deterioração pós-colheita dos frutos devido à freqüente contaminação dos ambientes de armazenagem, entrepostos de distribuição e venda de frutos pelo etileno e/ou outros gases poluentes com ação semelhante à do etileno (ex: propileno).

O inibidor da ação do etileno 1-MCP (1-metilciclopropeno) efetivamente reduz a produção de etileno, retarda a maturação e estende a vida pós-colheita de inúmeras espécies de frutos climatéricos (Blankenship \& Dole, 2003). Trabalhos recentes demonstram que o tratamento 1-MCP aumenta a conservação pós-colheita de caquis adstringentes (Nakano et al., 2002; 2003; Tsviling et al., 2003; Salvador et al., 2004) e não-adstringentes (Argenta et al., 2002; Brackmann et al., 2003). Entretanto, vários fatores podem afetar a eficácia do tratamento com 1-MCP, incluindo o estádio de maturação dos frutos na colheita
(Argenta et al., 2005).

O objetivo deste trabalho foi avaliar os efeitos do tratamento com 1-MCP sobre a conservação da qualidade de caquis 'Fuyu' colhidos em diferentes estádios de maturação e mantidos a $23^{\circ} \mathrm{C}$ após a colheita. Adicionalmente, foi estimado o impacto da exposição dos frutos ao etileno exógeno sobre a eficácia do tratamento pós-colheita com 1-MCP.

\section{MATERIAL E MÉTODOS}

Caquis (Diospyros kaki) da cultivar Fuyu foram colhidos em 2002 e 2003, em pomar comercial de Fraiburgo-SC, implantado em 1992 sob porta-enxerto procedente de semente. Os frutos foram colhidos entre 10 de abril e 25 de maio e classificados visualmente em quatro diferentes estádios de desenvolvimento de acordo com a coloração da casca: Estádio 2(E2): Fruto maduro-incipiente, com coloração verde-amarela (frutos com superfície predominantemente verde e com menos de 50\% da superfície amarela); Estádio 3 (E3): Fruto meio-maduro, com coloração amareloverde (frutos com superfície predominantemente amarela e com menos de 50\% da superfície verde); Estádio 4 (E4): Fruto meio-maduro, com coloração amarelo-laranja (frutos com superfície predominantemente amarela e com menos de 50\% da superfície laranja); Estádio 5 (E5): Fruto maduro, com coloração laranja-amarela (frutos com superfície predominantemente laranja e com menos de $50 \%$ da superfície amarela);

\section{Tratamentos com 1-MCP}

Um dia após a colheita, os frutos foram tratados com 0; 0,1 e $1,0 \mu \mathrm{L} \cdot \mathrm{L}^{-1}$ de 1-MCP (1-metilciclopropeno), em câmaras herméticas de 1 $\mathrm{m}^{3}$, por 24 horas, sob temperatura ambiente. Gás de 1-MCP foi produzido, misturando-se SmartFresh ${ }^{\mathrm{TM}}$ (AgroFresh Inc.) e água num frasco de $150 \mathrm{~mL}$ conectado à câmara de tratamento. Gás de 1-MCP foi bombeado para a câmara de tratamento num sistema fechado, por um período (menor que $15 \mathrm{~min}$ ) necessário para alcançar as concentrações desejadas. As concentrações de 1-MCP no ar das câmaras de tratamento foram determinadas por cromatografia gasosa, usando-se gás 1-MCP

\footnotetext{
${ }^{1}$ (Trabalho 108/2005). Recebido: 08/07/2005. Aceito para publicação: 21/11/2005

2 Epagri/Estação Experimental de Caçador, C.P. 591, 89500-000 Caçador-SC, fone: (49) 561-2000, e-mail: ju.golin@bol.com.br; argenta@epagri.rct-sc.br e marjv@bol.com.br
} 
(AgroFresh Inc., PA, USA) como padrão (Argenta et al., 2003b).

\section{Armazenagem}

Em 2002 e 2003, após o tratamento com 1-MCP, os frutos foram mantidos sob temperatura controlada a $23 \pm 2{ }^{\circ} \mathrm{C}$, umidade relativa (UR) de $75 \pm 5 \%$ por até 45 dias, em atmosfera com baixo etileno (d" $0,1 \mu \mathrm{L} \cdot \mathrm{L}$ $\left.{ }^{1}\right)$. Alternativamente, em 2003, os frutos foram mantidos sob atmosfera do ar com $3 \pm 2 \mu \mathrm{L} \cdot \mathrm{L}^{-1}$ de etileno. A temperatura e a UR do ar média para os períodos experimentais de ambos os anos foram determinadas a partir de registros contínuos em termógrafo (Sigma-II, SK Co., Japão) aferido por psicrômetro (Belfort Inst. Com., Estados Unidos). A atmosfera com baixo (d" $0,1 \mu \mathrm{L} \cdot \mathrm{L}^{-1}$ ) etileno formou-se pela evolução de etileno dos caquis armazenados e/ou por eventual contaminação externa, enquanto a atmosfera com alto $\left(3 \mu \mathrm{L} \cdot \mathrm{L}^{-1}\right)$ etileno foi obtida mantendose aproximadamente $120 \mathrm{~kg}$ de maçãs no ambiente de armazenagem.

\section{Análises dos frutos}

$\mathrm{Na}$ colheita e durante a armazenagem a $23^{\circ} \mathrm{C}$, os frutos foram analisados quanto à coloração da casca, firmeza da polpa, teor de sólidos solúveis totais (SST), acidez titulável (AT) e produção de etileno. A cor da casca foi determinada em três posições da superfície de cada fruto, duas medidas em dois lados opostos da região equatorial e uma medida na superfície distal ao cálice através do colorímetro CR300 (Minolta, Tokyo) e descrita como ângulo hue (MacGuire, 1992). Os teores de SST e a AT no suco foram determinados, usando-se refratômetro digital (Atago, Tokyo) e pela titulação com $\mathrm{NaOH}$ 0,1 N até $\mathrm{pH}$ 8,2, usando-se um titulador automático (Radiometer, Lyon, França), respectivamente. A análise objetiva da firmeza da polpa foi realizada em três lados da superfície de cada fruto, pela utilização de um penetrômetro com ponteira de $8 \mathrm{~mm}$ de diâmetro (Güss, África do Sul), enquanto a análise subjetiva (não-destrutiva) da firmeza da polpa foi realizada pelo tato das mãos. Frutos moles foram considerados aqueles que poderiam ser facilmente amassados pelas mãos. A firmeza da polpa de frutos identificados pelo tato como muito moles foi sempre inferior ao nível de detecção $(2,2 \mathrm{~N})$ quando avaliada pelo penetrômetro. A taxa de produção de etileno foi determinada em amostras de frutos colocadas em jarras de $4 \mathrm{~L}$, supridas com ar comprimido, livre de etileno, à taxa de $100 \mathrm{~mL} \cdot \mathrm{min}^{-1}$, e mantidas a $23^{\circ} \mathrm{C}$. A concentração de etileno no ar efluente foi determinada por meio de um cromatógrafo a gás conforme descrito em Argenta et al. (2003b).

\section{Análises estatísticas}

O delineamento experimental usado foi o de blocos casualizados, com 20 repetições, sendo a unidade constituída por um fruto, para análises da cor da casca e da firmeza da polpa. Para a análise não-destrutiva da firmeza da polpa, foram utilizadas três repetições de 20 frutos. As determinações de SST, AT e de produção de etileno foram feitas utilizando cinco frutos, com quatro repetições. Os dados foram sujeitos à análise de variância, e a diferença mínima significativa (DMS) entre tratamentos foi determinada pelo teste de Fisher $(\alpha=0,05)$.

\section{RESULTADOS E DISCUSSÃO}

\section{Maturação na colheita}

As diferenças de cor da casca (ângulo hue) e do teor de sólidos solúveis totais (SST) indicaram que, em 2002, frutos colhidos no estádio 5 estavam mais maduros que frutos no estádio 3, embora apresentassem firmeza da polpa semelhante (Tabela 1). Em 2003, frutos colhidos no estádio 4 estavam significativamente mais maduros que frutos no estádio 2, conforme indicado pela cor da casca, teor de SST e firmeza da polpa.

TABELA 1 - Índice de cor hue, firmeza da polpa e conteúdo de sólidos solúveis totais no dia da colheita de caquis 'Fuyu' classificados pela cor da casca em diferentes estádios de maturação, em 2002 e 2003.

\begin{tabular}{cccccccc}
\hline $\begin{array}{c}\text { Estádios } \\
\text { de }\end{array}$ & \multicolumn{3}{c}{2002} & & \multicolumn{3}{c}{2003} \\
\cline { 2 - 3 } maturação & $\begin{array}{c}\text { Ângulo } \\
\text { hue }\end{array}$ & $\begin{array}{c}\text { Firmeza } \\
(\mathrm{N})\end{array}$ & $\begin{array}{c}\text { SST } \\
(\%)\end{array}$ & & $\begin{array}{c}\text { Ângulo } \\
\text { hue }\end{array}$ & $\begin{array}{c}\text { Firmeza } \\
(\mathrm{N})\end{array}$ & $\begin{array}{c}\text { SST } \\
(\%)\end{array}$ \\
\hline 2 & & & & & 82,9 & 73,2 & 13,3 \\
3 & 75,4 & 65,7 & 15,0 & & 78,6 & 73,2 & 14,2 \\
4 & 70,0 & 63,7 & 15,2 & & 70,5 & 66,4 & 14,6 \\
5 & 65,9 & 62,5 & 15,7 & & & \\
\hline DMS $^{1}$ & 2,89 & 1,54 & 0,63 & & 2,09 & 0,84 & 0,47 \\
\hline
\end{tabular}

${ }^{1}$ Diferença mínima significativa entre os estádios de maturação, determinada pelo teste de Fischer $(\alpha=0,05)$.

Efeitos interativos do estádio de maturação na colheita e tratamentos com 1-MCP e etileno

$\mathrm{O}$ amolecimento da polpa foi mais rápido em frutos colhidos nos estádios mais avançados de maturação, e o tratamento pós-colheita com 1-MCP retardou a maturação dos frutos (Figura 1). Todos os frutoscontrole colhidos no estádio 5 amoleceram, aproximadamente, em 14 dias após a colheita. Nesse período, o amolecimento da polpa ocorreu em $52 \%$ e $74 \%$ dos frutos-testemunha colhidos nos estádios 3 e 4 , respectivamente. Por outro lado, o amolecimento de $100 \%$ dos frutos tratados com 1-MCP ocorreu apenas após 35 dias, quando colhidos no estádio 5, enquanto nos estádios 3 e 4 , apenas $50 \%$ e $70 \%$ dos frutos tratados com 1-MCP amoleceram após 35 dias a $23^{\circ} \mathrm{C}$, respectivamente.

$\mathrm{O}$ efeito do estádio de maturação na colheita sobre a conservação de caqui foi evidente para ambos os anos. Em 2003, frutoscontrole colhidos no estádio 2 apresentaram firmeza maior que frutos colhidos no estádio 4, tanto na colheita (Tabela 1) como após 20 dias da colheita (Tabela 2). Já frutos tratados com 1-MCP apresentaram firmeza da polpa $42,6 \mathrm{~N}$ e $23,5 \mathrm{~N}$ superior ao controle quando colhidos nos estádios 2 e 4, respectivamente, após 20 dias da colheita (Tabela 2).

A taxa de perda da firmeza da polpa de caqui, durante a

TABELA 2 - Firmeza da polpa (N) de caquis ‘Fuyu’ colhidos e classificados pela cor da casca em diferentes estádios de maturação, em 2002 e 2003 , após 20 dias a $23^{\circ} \mathrm{C}$.

\begin{tabular}{|c|c|c|c|c|c|c|c|}
\hline \multirow{3}{*}{ Estádios de maturação (E) } & \multicolumn{4}{|c|}{2002} & \multicolumn{3}{|c|}{2003} \\
\hline & \multirow[t]{2}{*}{ Controle } & \multicolumn{2}{|c|}{$1-M C P$} & \multirow[t]{2}{*}{$\mathrm{DMS}^{1}$} & \multirow[t]{2}{*}{ Controle } & \multirow{2}{*}{$\frac{1-\mathrm{MCP}}{1 \mu \mathrm{L} \cdot \mathrm{L}^{-1}}$} & \multirow[t]{2}{*}{$\mathrm{DMS}^{1}$} \\
\hline & & $0,1 \mu \mathrm{L} \cdot \mathrm{L}^{-1}$ & $1 \mu \mathrm{L} \cdot \mathrm{L}^{-1}$ & & & & \\
\hline 2 & & & & & 26,2 & 68,9 & 2,3 \\
\hline 3 & $<2,2^{3}$ & 29,8 & 47,3 & 1,3 & 20,3 & 54,2 & 2,3 \\
\hline 4 & $<2,2$ & 30,2 & 29,7 & 1,3 & 16,7 & 40,4 & 2,5 \\
\hline 5 & $<2,2$ & 19,6 & 27,1 & 1,2 & & & \\
\hline $\mathrm{DMS}^{1}$ & & 1,8 & 1,4 & & 2 & 2,5 & \\
\hline Ex Tratamento ${ }^{2}$ & & $* * *$ & & & $*$ & & \\
\hline $\mathrm{Ano}^{2}$ & & & & $* * *$ & & & \\
\hline Ano x Tratamento ${ }^{2}$ & & & & ns & & & \\
\hline
\end{tabular}

${ }^{1}$ Diferença mínima significativa entre os tratamentos, determinada pelo teste de Fischer $(\alpha=0,05)$.

${ }^{2}$ Efeito e interação determinados para frutos nos estádios 3 e 4 e tratados com $1 \mu \mathrm{L} \cdot \mathrm{L}^{-1}$ de $1-\mathrm{MCP}$.

$\mathrm{ns}, * * *, * * *=$ não significativo ou significativo a $5 \%, 1 \%$ e $0,1 \%$, pelo teste $\mathrm{F}$.

${ }^{3}$ Frutos com firmeza inferior ao nível de detecção instrumental $(2,2 \mathrm{~N})$. 


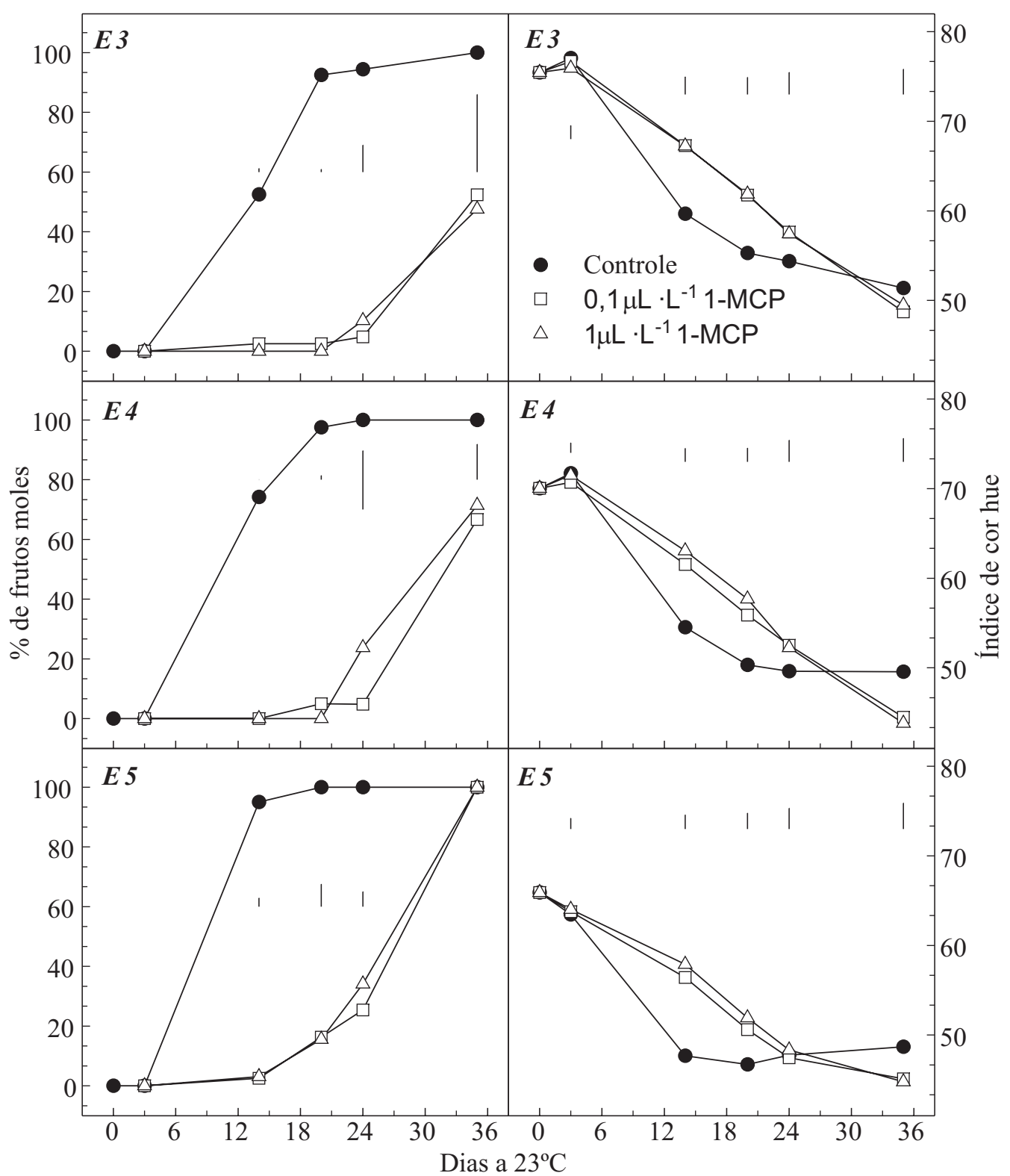

FIGURA 1 - Percentagem de frutos moles analisados subjetivamente pelo tato, e índice de cor hue de caquis 'Fuyu' colhidos e classificados visualmente pela cor da casca. (E3): fruto meio-maduro, superfície amarelo-verde ( $>50 \%$ amarelo); (E4): fruto meio-maduro, superfície amarelo-laranja (> 50\% amarelo); (E5): fruto maduro, superfície laranja-amarela (> 50\% laranja). Um dia após a colheita, frutos foram tratados com 0 (controle); 0,1 ou $1 \mu \mathrm{L} \cdot \mathrm{L}^{-1}$ de $1-\mathrm{MCP}$ e, então, mantidos a $23^{\circ} \mathrm{C}$ por até 35 dias, em ar ambiente contendo baixa $\left(\mathrm{d}^{\prime \prime} 0,1 \mu \mathrm{L} \cdot \mathrm{L}^{-1}\right)$ concentração de etileno. As barras verticais internas representam as diferenças mínimas significativas (DMS, $\alpha=0,05)$ entre tratamentos.

maturação a $23^{\circ} \mathrm{C}$, também variou entre anos (Tabela 2). Frutos colhidos nos estádios 3 e 4, em 2002, amoleceram mais rapidamente que frutos colhidos nos estádios 3 e 4, em 2003, independentemente do tratamento com 1-MCP. Isso se deve, em parte, ao fato de que, na colheita, a firmeza da polpa foi sensivelmente maior em 2003 que em 2002, apesar de os frutos apresentarem a cor da casca semelhante (Tabela 1).

O amolecimento da polpa dos frutos iniciou antes do aumento climatérico da produção de etileno, embora tanto o aumento acentuado da produção de etileno quanto a redução acentuada da firmeza da polpa fossem retardados por aproximadamente 10 dias pelo tratamento com 1MCP (Figura 2).

Frutos-testemunha expostos ao alto $\left(3 \mu \mathrm{L} \cdot \mathrm{L}^{-1}\right)$ etileno amoleceram e desenvolveram cor vermelha em 5 dias a $23^{\circ} \mathrm{C}$ (Figura 3 ). Por outro lado, apenas parte $(20 \%$ a $55 \%)$ dos frutos tratados com 1 MCP e expostos a $3 \mu \mathrm{L} \cdot \mathrm{L}^{-1}$ de etileno amoleceram depois de 25 dias, indicando que o benefício do tratamento com 1-MCP sobre o retardamento da maturação pode ser mais evidente para frutos armazenados em ambiente contendo alta concentração de etileno (Figura 3). Tratamento com 1-MCP retardou o amolecimento em aproximadamente 20 dias para frutos colhidos no estádio 5 e mantidos sob baixa concentração (d" $\left.0,1 \mu \mathrm{L} \cdot \mathrm{L}^{-1}\right)$ de etileno (Figura 1) e em mais de 20 dias para frutos colhidos no mesmo estádio de maturação e expostos

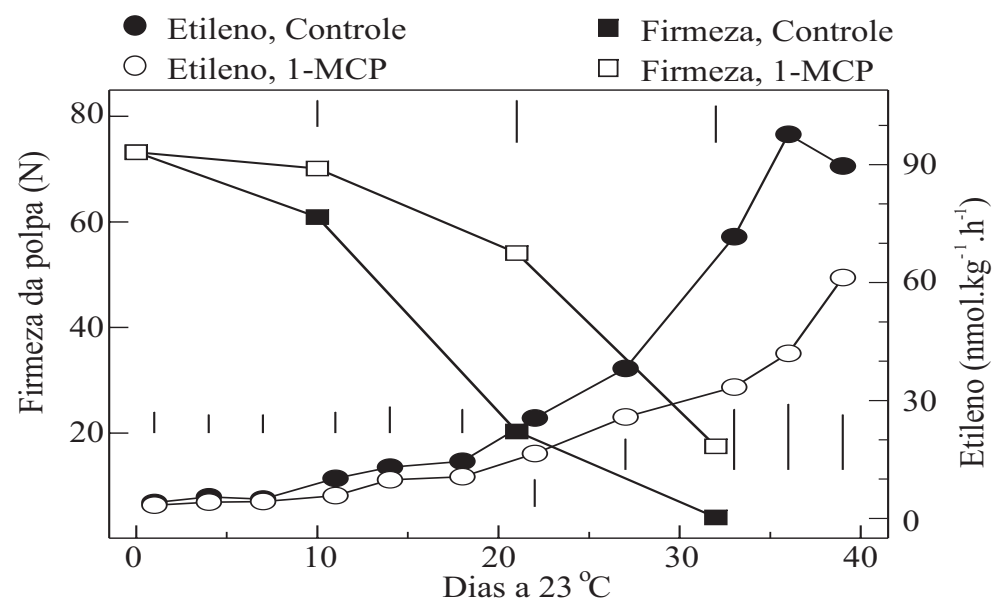

FIGURA 2 - Firmeza da polpa e produção de etileno de caquis 'Fuyu' mantidos a $23^{\circ} \mathrm{C}$ após a colheita. Frutos foram colhidos no estádio 3 de maturação. (E3): fruto meio-maduro, superfície amarelo-verde ( $>50 \%$ amarelo). Um dia após a colheita, frutos foram tratados com 0 (controle) ou $1 \mu \mathrm{L} \cdot \mathrm{L}^{-}$ ${ }^{1}$ de 1 -MCP. As barras verticais internas representam as diferenças mínimas significativas (DMS, $\alpha=0,05)$ entre tratamentos para firmeza (no topo) e para a produção de etileno (na base). 


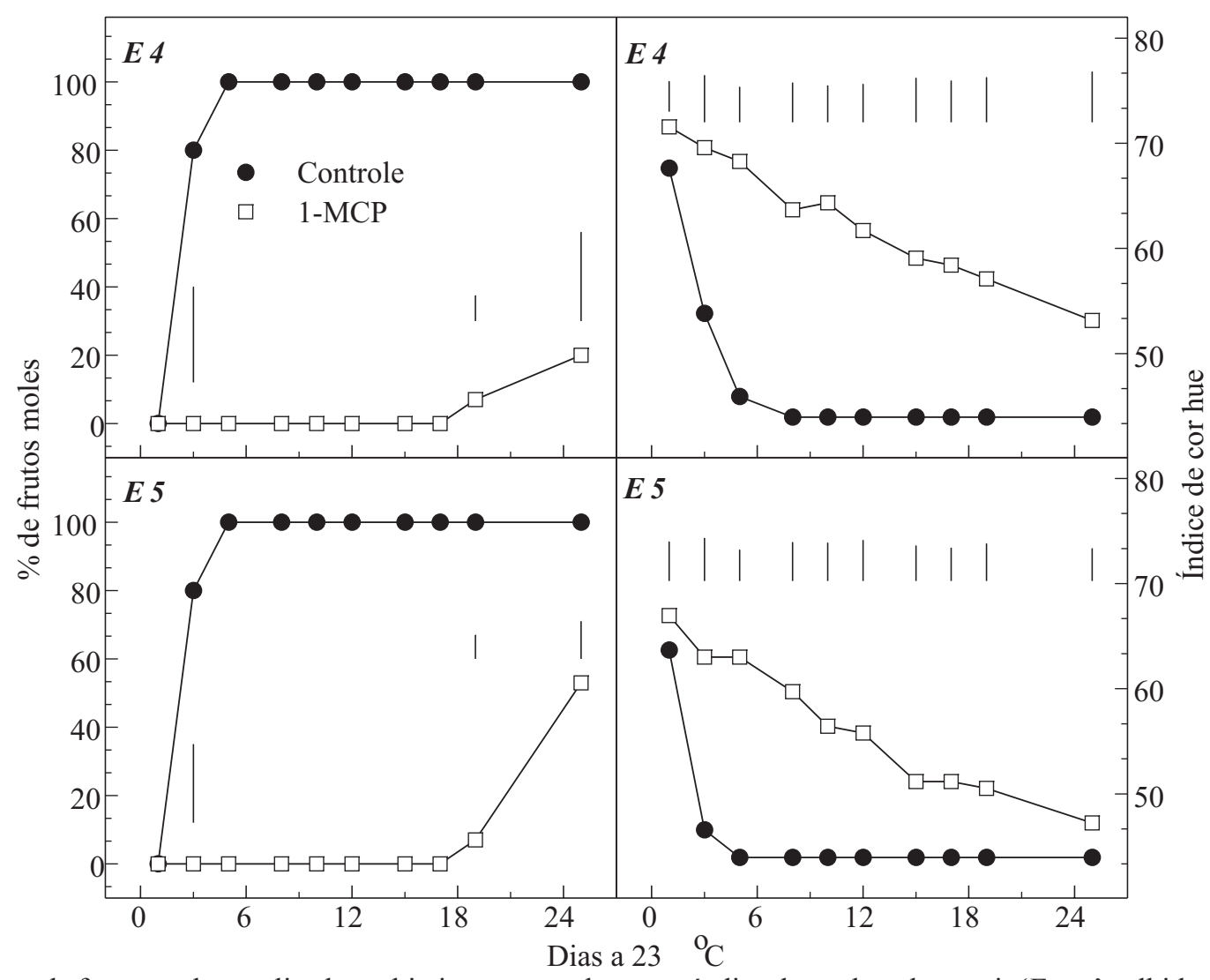

FIGURA 3 - Percentagem de frutos moles analisados subjetivamente pelo tato, e índice de cor hue de caquis 'Fuyu' colhidos em 2003 e classificados visualmente pela cor da casca nos estádios E4 e E5. (E4): fruto meio-maduro, superfície amarelo-laranja ( $>50 \%$ amarelo); (E5): fruto maduro, superfície laranja-amarela (> $>0 \%$ laranja). Um dia após a colheita, frutos foram tratados com 0 (controle) ou $1 \mu \mathrm{L} \cdot \mathrm{L}^{-1} \mathrm{de} 1-\mathrm{MCP}$ e, então, expostos a $3 \mu \mathrm{L} \cdot \mathrm{L}^{-1}$ de etileno durante armazenagem a $23^{\circ} \mathrm{C}$, por até 25 dias. As barras verticais internas representam as diferenças mínimas significativas (DMS, $\alpha=0,05)$ entre tratamentos.

ao alto etileno (Figura 3).

A inibição das respostas de caqui 'Fuyu' ao alto etileno exógeno por mais de 20 dias após o tratamento com 1-MCP, por apenas 24 horas, suporta a hipótese de que o 1-MCP se liga de forma irreversível ao sítio receptor do etileno (Sisler \& Serek, 1997). Apesar disso, frutos tratados com 1-MCP recuperaram a capacidade de produzir etileno e amadureceram (Figuras 1, 2 e 3), possivelmente, devido à síntese de novos sítios receptores do etileno (Blankenship \& Dole, 2003). Estudos anteriores demonstram que os efeitos do 1-MCP em banana (Golding et al., 1998) e peras (Argenta et al., 2003a) não são revertidos com a exposição dos frutos ao etileno.

O amolecimento da polpa é o principal indicador do fim da vida pós-colheita de caqui. Caqui 'Fuyu' normalmente é consumido ainda crocante, quando a firmeza for igual ou superior a $22 \mathrm{~N}$, especialmente na América do Norte e Europa (Sargent et al., 1993; Crisosto et al., 1999). Além disso, o processamento (classificação, empacotamento, etc.), transporte e distribuição dos frutos só são viáveis para frutos com firmeza superior ou igual a $17 \mathrm{~N}$ (Crisosto et al., 1999). A vida póscolheita de caquis mantidos a $20^{\circ} \mathrm{C}$ varia muito entre cultivares, podendo ser de até 20 dias para a cultivar 'Fuyu' (Sargent et al., 1993). Frutos de cultivares adstringentes podem amolecer em 4 a 10 dias após tratamento para a remoção da adstringência (Itamura et al., 1991 e 1997).

Em 2002, frutos não-tratados com 1-MCP atingiram firmeza de aproximadamente $22 \mathrm{~N}$ em menos de 14 dias após a colheita (Figura 1; Tabela 2) ou em menos de 5 dias após a colheita quando expostos ao alto etileno (Figura 3). Em 2003, frutos não-tratados com 1-MCP atingiram firmeza de aproximadamente $22 \mathrm{~N}$ em 20 dias após a colheita (Figura 2). Por outro lado, a redução da firmeza para próximo de $22 \mathrm{~N}$, em frutos tratados com 1-MCP, ocorreu entre 20 e 35 dias após a colheita, independentemente da exposição ao alto etileno. O retardamento do amolecimento da polpa de caqui pelo 1-MCP está associado à redução do acúmulo de mRNAs para celulases e poligalacturonases (Kubo et al., 2003).
O tratamento com 1-MCP retardou o amolecimento dos frutos colhidos em todos os estádios de maturação (Figura 1, Tabela 2) embora o benefício do tratamento 1-MCP na conservação da firmeza tenha sido significativamente menor para frutos colhidos em estádio avançado de maturação (Tabela 2). Os efeitos do 1-MCP também são menos pronunciados para banana (Harris et al., 2000), frutos de caroço (Fan et al., 2002), tomate (Wills \& Ku, 2002) e maçã (Argenta et al., 2005) quando colhidos e/ou tratados em estádios avançados de maturação. A efetividade do tratamento com 1-MCP pode ser alterada pelo estádio de maturação, possivelmente, porque os frutos se tornam mais sensíveis ao etileno com o avanço da maturação (Hartmann et al., 1987).

De maneira geral, a capacidade de produção de etileno aumenta, e a vida pós-colheita de frutos climatéricos diminui com o avanço da maturação. No presente estudo, caquis 'Fuyu' colhidos tardiamente amadureceram mais rapidamente que aqueles colhidos precocemente (Figura 1).

Caqui é um fruto climatérico, embora sua capacidade de produção de etileno seja reduzida exponencialmente com o avanço da maturação fisiológica (Takata, 1983; Itamura et al., 1997). Além disso, caqui colhido fisiologicamente imaturo pode apresentar menor vida póscolheita que aquele colhido fisiologicamente maduro (Itamura et al., 1997). No entanto, caqui colhido em estádio de maturação avançada, ou seja, após o ponto de colheita comercial, pode apresentar vida póscolheita curta, semelhante à de fruto fisiologicamente imaturo (Itamura et al., 1997). Estudos recentes indicam que o rápido amolecimento da polpa após a colheita de caqui fisiologicamente imaturo está associado à alta produção de etileno induzida pelo estresse hídrico nas sépalas (Nakano et al., 2002 e 2003). Aparentemente, caqui fisiologicamente imaturo exibe, após a colheita, dois picos de produção de etileno, sendo o primeiro induzido no cálice em resposta ao estresse hídrico nas sépalas e o segundo induzido na polpa em resposta à ação autocatalítica do etileno produzido no cálice (Nakano et al., 2002 e 2003). O tratamento com 1-MCP não reduz a produção de etileno pelo cálice, mas inibe sua 


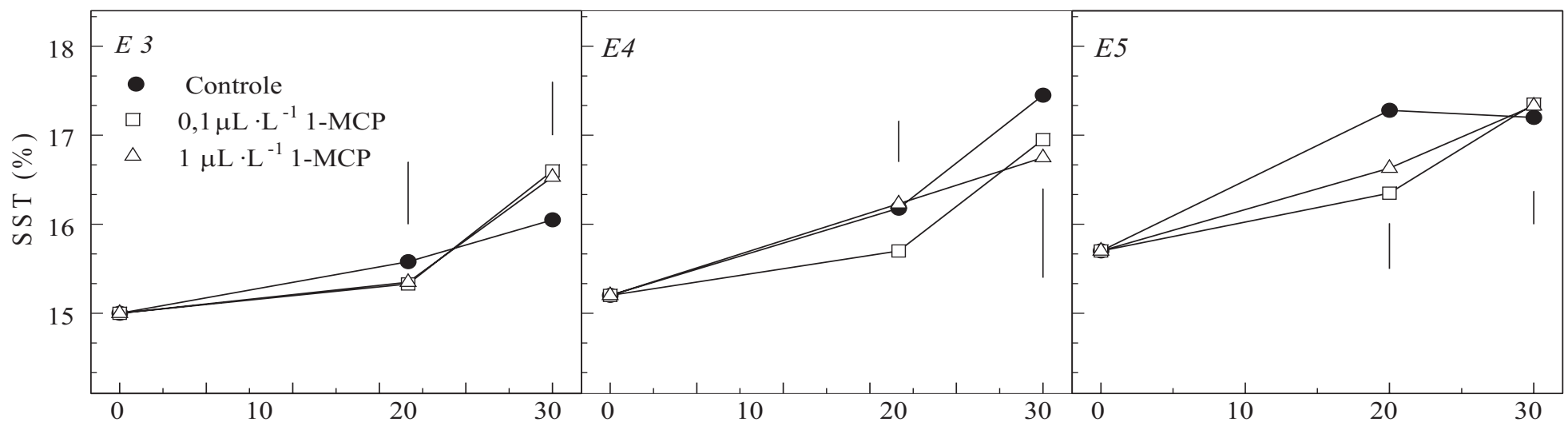

FIGURA 4 - Conteúdo de sólidos solúveis totais (SST) de caquis 'Fuyu' colhidos em 2002 e classificados visualmente pela cor da casca. (E3): fruto meio-maduro, superfície amarelo-verde (> 50\% amarelo); (E4): fruto meio-maduro, superfície amarelo-laranja (> 50\% amarelo); (E5): fruto maduro, superfície laranja-amarela $\left(>50 \%\right.$ laranja). Um dia após a colheita, frutos foram tratados com 0 (controle); 0,1 ou $1 \mu \mathrm{L} \cdot \mathrm{L}^{-1} \mathrm{de}$ $1-\mathrm{MCP}$ e, então, armazenados a $23^{\circ} \mathrm{C}$ por até 30 dias. As barras verticais internas representam as diferenças mínimas significativas (DMS, $\alpha=0,05)$ entre tratamentos.

ação, prevenindo a produção de etileno na polpa e o amolecimento dos frutos (Nakano et al., 2002 e 2003). No presente estudo, não foi evidenciado o primeiro pico de produção de etileno durante os primeiros três dias após a colheita conforme observado nas pesquisas anteriores (Figura 2), possivelmente porque os frutos foram armazenados sob umidade relativa suficientemente alta $(>70 \%)$ para prevenir o estresse hídrico.

O retardamento do amolecimento da polpa pelo inibidor da ação do etileno 1-MCP (Figura 1) e a antecipação do amolecimento pela exposição a alta concentração de etileno (Figura 3) confirmam o papel regulador do etileno sobre a maturação pós-colheita de caqui 'Fuyu'. No entanto, o início do amolecimento da polpa precedeu o começo do aumento autocatalítico da produção de etileno (Figura 2). Em caqui 'Tonewase' e 'Saijo', o amolecimento da polpa ocorre logo após o aumento da produção de etileno induzida pelo estresse hídrico, mas antes do aumento climatérico da produção de etileno (Nakano et al., 2002 e 2003). Em caqui 'Hiratanenashi', o amolecimento da polpa coincide ou inicia logo após o aumento da produção de etileno quando os frutos são tratados com propileno ou etanol para a remoção da adstringência, mas começa antes do aumento da produção de etileno em frutos nãotratados (Itamura et al., 1991; Kubo et al., 2003). Aparentemente, o início da maturação dos frutos não está apenas associado ao aumento acentuado da produção de etileno, mas também ao aumento da sensibilidade dos frutos ao etileno endógeno (MacGlasson, 1985). O papel regulador do etileno sobre a maturação de caqui também é demonstrado pelo aumento da vida pós-colheita dos frutos armazenados sob atmosfera com baixo etileno (Maotani et al., 1982).

$\mathrm{O}$ tratamento com 1-MCP retardou o desenvolvimento da cor laranja-avermelhada dos frutos, independentemente do estádio de maturação na colheita (Figuras 1 e 3). No entanto, frutos tratados com 1-MCP apresentaram cor semelhante à de frutos-controle quando ocorreu o amolecimento da polpa (Figura 1). Os frutos-controle colhidos no estádio 5 apresentaram cor mais avermelhada (menor hue) que frutos colhidos no estádio 3 ou 4 quando amoleceram (Figura 1).

O teor de SST aumentou durante a maturação pós-colheita a $23^{\circ} \mathrm{C}$ e não foi alterado significativamente pelo tratamento com $1-\mathrm{MCP}$, independentemente do estádio de maturação na colheita (Figura 4). Exceção ocorreu para frutos colhidos no estádio 5, aos 20 dias após a colheita, quando frutos tratados com 1-MCP exibiram menor teor de SST. Quando amoleceram, frutos colhidos no estádio 5 tinham teores de SST maiores que frutos colhidos no estádio 3. Esses resultados indicam que o teor de SST e a coloração da superfície dos frutos após a armazenagem foram relativos à coloração e ao teor de SST na colheita, independentemente do tratamento com 1-MCP. O tratamento 1-MCP também não altera o teor de açúcares solúveis em caqui 'Quioto' e 'Rojo Brillante' (Brackmann et al., 2003; Salvador et al., 2004). Não houve efeito significativo do estádio de maturação na colheita nem do tratamento com 1-MCP sobre a taxa de perda da acidez no período póscolheita (dados não apresentados).

Efeito de doses de 1-MCP

Os tratamentos com 1-MCP foram igualmente efetivos, independentemente da dose e do ponto de colheita (Figuras 1 e 2). Exceção ocorreu após 20 dias de armazenagem (Tabela 2), quando frutos colhidos nos estádios 3 e 5 , tratados com $1 \mu \mathrm{L} \cdot \mathrm{L}^{-1}$ de $1-\mathrm{MCP}$, apresentaram maior firmeza que frutos tratados $\operatorname{com} 0,1 \mu \mathrm{L} \cdot \mathrm{L}^{-1}$, indicando que a saturação das respostas de caqui 'Fuyu' ao tratamento 1-MCP deve ocorrer sob concentração próxima ou ligeiramente superior a 0,1 $\mu \mathrm{L} \cdot \mathrm{L}^{-1}$. A dose de saturação das respostas ao $1-\mathrm{MCP}$ varia muito entre espécies de frutos e com outros fatores, incluindo o estádio de maturação no momento do tratamento e o período de armazenagem (Blankenship \& Dole, 2003; Argenta et al., 2005). Quando o tempo de tratamento é superior a $12 \mathrm{~h}$, a dose de saturação para muitas espécies de frutos, incluindo maçãs, peras, frutos de caroço e abacate, está entre 0,1 e $1 \mu \mathrm{L}$ $\cdot \mathrm{L}^{-1}$, mas pode ser menor que $0,1 \mu \mathrm{L} \cdot \mathrm{L}^{-1}$ para outras espécies de frutos, incluindo tomate e banana (Blankenship \& Dole, 2003).

\section{CONCLUSÕES}

1. O tratamento com 1-MCP retarda o amolecimento da polpa, o desenvolvimento da cor dos frutos e o aumento da produção de etileno, mas não tem efeito sobre o teor de açúcares solúveis.

2. O tratamento com 1-MCP estende a vida pós-colheita de caqui 'Fuyu' em até 20 dias em relação a frutos não-tratados, quando mantidos a $23{ }^{\circ} \mathrm{C}$ após a colheita.

3 . Os frutos colhidos tardiamente apresentam menor vida póscolheita, independentemente do tratamento com 1-MCP.

4. O benefício do tratamento 1-MCP é maior para frutos colhidos precocemente e para frutos expostos a alta concentração de etileno.

\section{AGRADECIMENTOS}

À CAPES e ao CNPq, pelas bolsas de estudos a Juliana Golin Krammes e Marcelo José Vieira; à AgroFresh Inc., pelo suporte financeiro, e ao professor Nei Fernandes Lopes, pela revisão deste trabalho.

\section{REFERÊNCIAS}

ARGENTA, L. C.; FAN, X.; MATTHEIS, J. Influence of 1methylcyclopropene on ripening, storage life, and volatile production by d'Anjou cv. pear fruit. Journal of Agricultural and Food Chemistry, Easton, v.51, p.3858-3864, 2003a.

ARGENTA, L. C.; FAN, X.; MATTHEIS, J.P. Factors affecting efficacy of 1-MCP to maintain quality of apples fruit after storage. Acta 
Horticulturae, Oostakker, v.682, p. 1249-1256, 2005.

ARGENTA, L.C.; KRAMMES, J.G.; MEGGUER, C.A.; AMARANTE, C.V.T; MATTHEIS, J.P. Ripening and quality of 'Laetitia' plums following harvest and cold storage as affected by inhibition of ethylene action. Pesquisa Agropecuária Brasileira, Brasília, v.38, n.10, p.1139-1148, 2003b.

ARGENTA, L. C.; KRAMMES, J. G.; MEGGUER, C.; CRESTÂNI, F. Aumento da conservação da qualidade pós-colheita de caqui e quivi pelo uso de 1-MCP. In: $\forall$ ENCONTRO NACIONAL SOBRE FRUTICULTURA DE CLIMA TEMPERADO, 5., 2002, Fraiburgo. Anais. Florianópolis: EPAGRI, 2002. p.170-174. não consigo arrmurrar esta referências

BLANKENSHIP, S.M.; DOLE, J.M. 1-Methylcyclopropene: a review. Postharvest biology and technology, Amsterdam, v.28, p.1-25, 2003.

BRACKMANN, A.; FRIETAS, S.T.; MELLO, A.M.; STEFFENS, C.A. Aplicação de 1-MCP em caqui ‘Quioto' armazenado sob refrigeração e atmosfera controlada. Revista Brasileira de Fruticultura, Jaboticabal, v.25, n.1, p.42-44, 2003.

CRISOSTO, C.H.; MITCHAM, E.J.; KADER, A.A. Recommendations for maintaining postharvest quality of horticultural commodities. Davis: University of California, 1999.

FAN, X.; ARGENTA, L.C.; MATTHEIS, J.P. Interactive effects of 1MCP and temperature on 'Elberta' peach quality. HortScience, Alexandria, v.37, p.134-138, 2002.

GOLDING, J.B.; SHEARER, D.; WYLLIE, S.G.; McGLASSON, W.B. Application of 1-MCP and propylene to identify ethylene-dependent ripening processes in mature banana fruit. Postharvest Biology and Technology, Amsterdam, v.12, p.87-98, 1998.

HARRIS, D.R.; SEBERRY, J.A.; WILLS, R.B.H.; SPOHR, L.J. Effect of fruit maturity on efficiency of 1-methylcyclopropene to delay the ripening of bananas. Postharvest Biology and Technology, Amsterdam. v.20, p.303-308, 2000.

HARTMANN, C.; DROUET, A.; MORIN, F. Ethylene and ripening of apple, pear and cherry fruit. Plant Physiology Biochemistry, Paris, v.25, p.505-512, 1987.

ITAMURA, H.; KITAMURA, T.; TAIRA, S.; HARADA, H.; ITO, N.; TAKAHASHI, Y.; FUKUSHIMA, T. Relationship between fruit softening, ethylene production and respiration in Japanese persimmon 'Hiratanenashi'. Journal of Japanese Society for Horticultural Science, Tokyo, v.60, n.3, p.695-701, 1991.

ITAMURA, H.; OHNO, Y.; YAMAMURA, H. Characteristics of fruit softening in Japanese persimmon 'Saijo'. Acta Horticulturae, The Hague, n.436, p.179-188, 1997.

KRAMMES, J.G. Aspectos fisiológicos da maturação e da qualidade de caqui 'Fuyu' na planta e após a colheita. 2004. 163f. Dissertação (Mestrado em Fisiologia Vegetal)- Universidade Federal de Pelotas, Pelotas, 2004.
KUBO, Y.; NAKANO, R.; INABA, A. Cloning of genes encoding cell wall modifying enzymes and their expression in persimmon fruit. Acta Horticulturae, The Hague, n.601, p.49-55, 2003.

MacGLASSON, W.B. Ethylene and fruit ripening. HortScience, Alexandria, v.20, n.1, p.51-53, 1985.

MacGUIRE, R.G. Reporting of objective color measurements. HortScience, Alexandria, v.27, p.1254-1255, 1992.

MacRAE, E.A. Development of chilling injury in New Zealand grown 'Fuyu' persimmon during storage. New Zealand Journal of Experimental Agriculture, Wellington, v.15: 333-344, 1987.

MAOTANI, T.; YAMADA, M.; KURIHARA, A. Storage of Japanese persimmon of pollination constant non-astringent type in polyethylene bags with ethylene absorbent. Journal of Japanese Society for Horticultural Science, Tokyo, v.51, p.195-202, 1982.

NAKANO, R.; INOUE, S.; KUBO, Y.; INABA, A. Water stress-induced ethylene in the calyx triggers autocatalytic ethylene production and fruit softening in 'Tonewase' persimmon grown in a heated plastic-house. Postharvest Biology and technology, Amsterdam, v.25, p.293-300, 2002

NAKANO, R.; KUBO, Y.; HARIMA, S.; INABA, A. Involvement of stress-induced ethylene biosynthesis in fruit softening of 'Saijo' persimmon fruit. Acta Horticulturae, The Hague, n.601, p.219-226, 2003.

SALVADOR, A.; ARNAL, L.; MONTERDE, A.; CUQUERELLA, J. Reduction of chilling injury symptoms in persimmon fruit cv. 'Rojo Brillante' by 1-MCP. Postharvest Biology and Technology, Amsterdam, v.33, p.285-291, 2004.

SARGENT, S.A.; CROCKER, T.E.; ZOELLNER, J. Storage characteristics 'Fuyu' persimmons. Proceedings of the Florida State Society for Horticultural Science, Tallahasse, v.106, p.131-134, 1993.

SISLER, E.C.; SEREK, M. Inhibitors of ethylene responses in plants at the receptor level: Recents developments. Physiologia Plantarum, Copenhagen, v.100, p.577-582, 1997.

TAKATA, M. Effects of ethylene on respiration, ethylene production and ripening of Japanese persimmon fruit harvested at various stages of development. Journal of Japanese Society for Horticultural Science, Tokyo, v.51, n.2, p.203-209, 1982.

TAKATA, M. Respiration, ethylene production and ripening of Japanese persimmon fruit harvested at various stages of development. Journal of Japanese Society for Horticultural Science, Tokyo, v.52, n.1, p.78-84, 1983.

TSVILING, A.; NERYA, O.; GIZIS, A.; SHARABI-NOV, A.; BEN-ARIE, R. Extending the shelf-life of 'Triumph' persimmons after storage, with 1-MCP. Acta Horticulturae, The Hague, n.599, p.53-58, 2003.

WILLS, R.B.H.; KU, V.V.V. Use of 1-MCP to extend the time to ripen of green tomatoes and postharvest life of ripe tomatoes. Postharvest Biology and Technology, Amsterdam, v.26, p.85-90, 2002. 